\title{
HADITH-HADITH DALAM BUKU MOTIVASI DI MALAYSIA (KAJIAN SANAD DAN MATAN)
}

\section{Muhammad Faiz Fathi Asmori, Mohd Arif Nazri, Haziyah Hussin}

Jabatan Pengajian al-Quran dan al-Sunnah, Fakulti Pengajian Islam

Universiti Kebangsaan Malaysia, 43600 UKM Bangi, Selangor Darul Ehsan, Malaysia faiz_fathi07@yahoo.com

\begin{abstract}
:
This article presents the research methodology of hadith in the motivation books in Malaysia. There are ten books have been collected and 149 of hadith that have been researched in this study. However, the researchers only studied 123 hadith, while 26 hadith are repeated. Based on the analysis of the status of 123 hadith, the researchers found 75 hadith were rated as maqbul hadith (Sahih and hasan), 42 hadith have had on the chain (sanad), and the remaining 6 hadith undetermined status. This study is a contribution to the writing of Islamic studies to enable the reader to know the status of the traditions set forth in motivational books whether it is accepted or rejected. In addition, this study also provides a set of guidelines for writers of motivational books genre to present hadith into their works. It would be beneficial to authors who have no background in Islamic studies and studies of hadith in producing better quality.
\end{abstract}

Keywords: Hadith, Motivation, Takhrij

\section{Pendahuluan}

Nabi Muhammad Shallalahu 'Alaihi Wasallam (SAW) merupakan individu agung yang diutuskan oleh Allah SWT sebagai pembawa berita gembira dan pemberi amaran. Sebagaimana firman Allah Subhanahu Wa Ta'ala (SWT) :

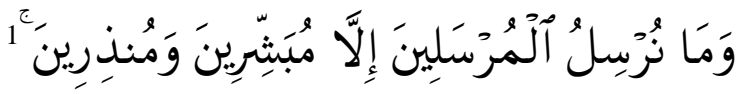

\footnotetext{
${ }^{1}$ Al-Quran, al-Kahfi 18: 56.

Url: http://jurnal.uin-antasari.ac.id/index.php/al-banjari/index DOI: http://dx.doi.org/10.18592/al-banjari.v16i1. 1072
} 
Maksud : Dan tidak kami mengutus rasul-rasul, melainkan sebagai pemberi berita gembira dan pemberi amaran. ${ }^{2}$

Sesuai dengan tujuan tersebut, maka Nabi Muhammad SAW menggunakan kata-kata dan contoh perbuatan bagi mendorong manusia ke arah mentaati Allah SWT dan mengancam mereka sekiranya mereka ingkar dan enggan mentaatiNya. Sebagaimana firman Allah SWT :

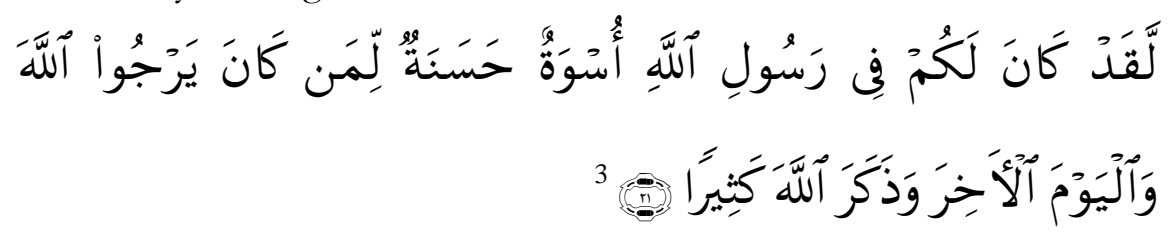

Maksud : Demi sesungguhnya, adalab bagi kamu pada diri Rasulullab itu contoh ikutan yang baik, iaitu bagi orang yang sentiasa mengharapkan (keredaan) Allah dan (balasan baik) hari akbirat, serta ia pula menyebut dan mengingati Allah banyak-banyak. (dalam masa susab dan senang).

Pada era Nabi Muhammad SAW dilantik oleh Allah SWT menjadi Nabi dan Rasul akhir zaman, baginda berjaya memotivasikan dan mengubah masyarakat Arab Jahiliyyah daripada kegelapan kepada cahaya Islam yang jelas. Kemampuan Rasulullah SAW dalam memotivasikan masyarakat Arab Jahiliyyah dibantu dengan kata-kata dan janji-janji yang diwahyukan oleh Allah SW'T. Justeru, ia menolak dakwaan bahawa apa yang dituturkan oleh Rasulullah adalah dengan mengikut hawa nafsu semata. Ia turut ditegaskan dalam firman Allah SWT :

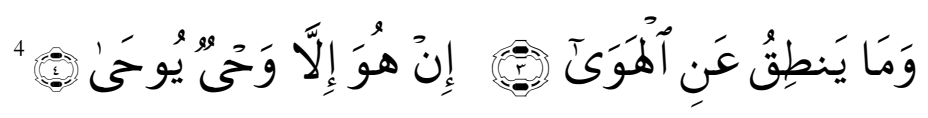

Maksud : Dan ia tidak memperkatakan (sesuatu yang berbubung dengan agama Islam) menurut kemabuan dan pendapatnya sendiri. Segala yang diperkatakannya itu (sama ada al-Quran atau badith) tidak lain hanyalah wahyu yang diwahyukan kepadanya.

Jika dilihat pada sejarah, para sahabat dilihat begitu bersemangat dan penuh dengan motivasi dalam kehidupan seharian mereka. Jika mereka ditimpa

\footnotetext{
2 Semua terjemahan al-Quran dalam tulisan ini berdasarkan Tafsir Pimpinan al-Rabman kepada Pengertian al-Quran, Edisi Kedua Belas, (Kuala Lumpur: Jabatan Kemajuan Islam Malaysia (JAKIM), 2001).

3 Al-Quran, al-Ahzab 33: 21.

4 Al-Quran, al-Najm 53: 3-4.
} 
masalah dan dirundung kelesuan jiwa, maka Rasulullah SAW merupakan tempat untuk mereka mengadu. Apabila mereka diceritakan tentang kebaikan, pasti mereka akan segera melakukannya tanpa ditangguh dan apabila mereka dilarang melakukan sesuatu perbuatan, mereka terus meninggalkannya. Sebagaimana disebut di dalam hadith :

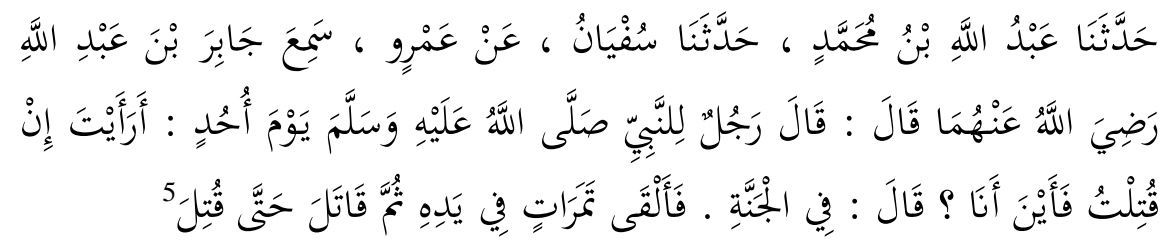

Maksud : Telah menceritakan kepada kami Abdullah bin Muhammad, telah menceritakan kepada kami Sufyan, daripada Amru, dia telah mendengar Jabir bin Abdullah radiyallah 'anbu (RA), beliau berkata: "Pada peperangan Ubud, seorang lelaki telah bertanya kepada Nabi SAW: "Adakah engkau tabu sekiranya aku terbunub, dimanakah tempatku?" Baginda bersabda: "Di dalam Syurga." Kemudian dia melemparkan buah tamar yang ada di tangannya, lalu dlia pergi berperang sehingga mati terbunuh. ${ }^{16}$ (Riwayat al-Bukhari)

Hadith di atas menunjukkan bahwa motivasi Rasulullah SAW sangat memberi kesan kepada para sahabat sehingga mereka terus melaksanakannya. Hal ini karena sumber motivasi mereka adalah Allah dan Rasul dan mereka yakin bahwa janji Allah dan Rasul itu benar.

Pada era modern dan globalisasi kini, wujudnya golongan dari umat Islam yang berusaha mengaplikasikan bentuk dan gaya motivasi Rasulullah di dalam memotivasikan manusia. Yakni dengan menggunakan hadis-hadis yang merupakan warisan baginda kepada umatnya. Sebagai contoh sebuah buku yang diterbitkan pada tahun 2012, bertajuk "Motivasi Gaya Rasulullab" ditulis oleh Mohd Khairul Nizam. Buku ini mengupas teknik motivasi yang digunakan oleh Rasulullah antaranya mempunyai unsur-unsur ganjaran dan ancaman dan lain-lain. Di dalam buku ini dibawakan hadith-hadith yang membincangkan akan hal tersebut. Terdapat juga buku-buku lain yang menggunakan gaya penulisan tersebut sebagaimana berikut:

1. Super Health Gaya Hidup Sehat Rasulullah (2007) oleh Egha Zainur Ramadhani

\footnotetext{
${ }^{5}$ Al-Bukhariyy, 1423H/2002M, 64-Kitab al-Maghaziyy, 17-Bab Ghuzwat Uhud, no. 4046, hlm. 994.

${ }^{6}$ Semua terjemahan al-Hadith dalam tulisan ini dibuat oleh pengkaji dengan bantuan daripada penyelia iaitu Dr. Mohd Arif bin Nazri kecuali kalau dinyatakan sebaliknya.
} 
2. Gaul Gaya Rasul (2009) oleh Aisha Chuang

3. Didik. Anak Gaya Rasulullab (2010) oleh Dr. Huzaemah

4. Buat Pahala "Free" Gaya Rasulullab (2014) oleh Mohd Khairul Nizam

5. Sehat Gaya Rasul (2014) oleh Dr. Sagiran

Demikian merupakan beberapa buku yang dijumpai oleh pengkaji, dan pengkaji yakin bahawa penulisan jenis ini banyak di pasaran dan sedang pesat dijalankan. Ia merupakan satu usaha yang baik. Tujuannya agar manusia masa kini mampu mengharungi dan menghadapi dunia yang penuh dengan ujian sesuai dengan petunjuk yang telah Rasulullah gariskan.

\section{Permasalahan Kajian}

Di Malaysia, hampir $34.42 \%$ hadith dhaif dan mawdu' yang sering digunakan oleh masyarakat Melayu di Malaysia. Dapatan ini didedahkan oleh Prof. Datin Paduka Dr. Jawiah Dakir dari Fakulti Pengajian Islam melalui syarahan perdana beliau yang bertajuk, "Keberadaan al-Mawdu dalam Masyarakat Melayu". Hasil dapatan kajian beliau berdasarkan kepada 825 hadith yang popular di kalangan masyarakat Melayu, yang mana 285 hadith daripadanya adalah mawdu'?

Beliau juga menambah bahawa hadith palsu terbabit bukan sahaja diperkatakan oleh orang yang tidak mempunyai kelayakan agama tetapi juga disampaikan oleh mereka yang diiktiraf dalam bidang agama. Ia turut diselitkan dalam khutbah Jumaat di seluruh negara, dalam kitab bahasa Arab, buku motivasi dan buku mengenai hari-hari penting dalam Islam seperti Israk dan Mikraj. Selain itu, ia juga kedengaran di kaca TV dan radio. Hal ini berlaku kerana hadith-hadith tersebut senantiasa diulang tanpa usul periksa akan status hadith tersebut. ${ }^{8}$ Sebagaimana contoh hadith yang disandarkan kepada Rasulullah s.a.w tanpa disebutkan sumber pengambilannya, ia disampaikan oleh Dato' Dr. Hj. Mohd. Fadzilah Kamsah sendiri di dalam sebuah rancangan motivasi terbitan saluran Astro Oasis yaitu: "Berbuat baik kepada oramg tuamu, agar anak-anakmu berbuat baik kepadamu"

Ia merupakan suatu perkara yang perlu diambil perhatian kerana menyandarkan sesuatu pernyataan kepada Nabi s.a.w sedangkan pernyataan

\footnotetext{
${ }^{7}$ Jawiah Dakir, 2014, hlm. 62.

8 Shahfizal Musa, 2014. Syarahan Perdana :Hadis Palsu dalam Masyarakat Melayu. http://www.ukm.my/news/News_Category/syarahan-perdana/ [15 September 2014]

9 Mienfitri, 2008M (September 22), Penawar Hati 2 - Ransang Perubahan (Astro Oasis), http://www.youtube.com/watch?v $=\mathrm{m} 614 \mathrm{vXM} 6 \mathrm{fAg}$, $\min$. 3:10. [21 Jun 2012]
} 
tersebut tiada sandaran merupakan kesalahan besar. Hal ini dikwatirkan akan menyebabkan berlakunya penyebaran hadith daif dan maudhu' dalam kalangan masyarakat sedangkan mereka tidak mengetahuinya.

Fenomena ini wajar ditangani agar umat Islam tidak terus menerus dihidangkan dengan hadith daif dan maudhu'. Untuk menjaga kesahihan dan kedudukan hadith Rasulullah SAW agar terus dihormati dan disanjung, beliau menyarankan agar kajian ilmiah berkaitan hadith daif dan maudhu' terus dipertingkatkan bagi menapis hadith-hadith yang tidak bersumber daripada Rasulullah SAW..$^{10}$

Muktakhir ini, sebuah laporan akhbar oleh Mahaizura Abd Malik dari akhbar tempatan juga telah menimbulkan isu berkaitan dengan hadith palsu yang tersebar secara meluas melalui aplikasi Whatsapp, Twitter, dan Telegram. ${ }^{11}$ Menurut laporan tersebut, penyebaran hadith palsu menjadi pantas seiring dengan perkembangan telefon pintar melalui pelbagai aplikasi yang terdapat di telefon pintar.

Prof. Madya Dr. Ishak Sulaiman turut mengulas pada laporan tersebut, menjadi budaya bagi masyarakat kini untuk berkongsi maklumat kepada rekan dan keluarga termasuk menyampaikan hadith-hadith palsu dengan tujuan untuk berkongsi kebaikan dan memberi motivasi. Namun tanpa sedar telah melakukan dosa besar. Hal ini kerana menyebarkan hadith-hadith palsu dikira sebagai berdusta atas nama Rasulullah SAW dan mendapat ancaman balasan di neraka. Sebagaimana sabda Baginda SAW :

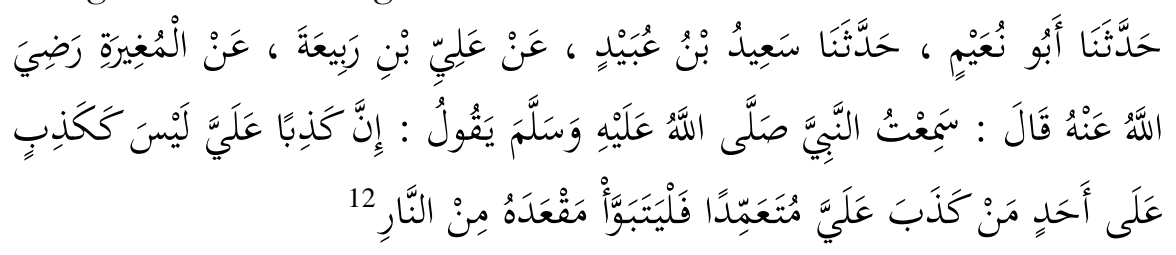

Maksud : Telah menyampaikan kepada kami Abu Nu'aym, telah menyampaikan kepada kami Sa'id bin 'Ubayd, daripada Ali bin Rabi'ah, daripada al-Mughirah $\mathrm{R} A$, beliau berkata: "Aku mendengar Nabi s.a.w bersabda: "Sesunggubnya berdusta keatasku tidak sama seperti berdusta dengan seseorang, barangsiapa yang berdusta keatasku secara sengaja, maka sediakanlah tempatnya dalam Neraka." (Riwayat al-Bukhariyy)

\footnotetext{
${ }^{10}$ Jawiah Dakir, 2014M, hlm. 73.

11 Mahaizura Abd Malik, 2015, hlm. 6. Rujuk juga : http://bit.ly/metro14ogos [14 Ogos 2015].

12 Al-Bukhariyy, 1417H/1997M, Jil. 1, 23-Kitab al-Jana'iz, 33-Bab Ma Yukrahu Mina alNihayah 'ala al-Mayyit, no. 1291, hlm. 385.
} 
Persatuan Ulama' Malaysia (PUM) turut memandang serius laporan dan fenomena penyebaran hadis palsu yang berlaku dalam kalangan rakyat Malaysia. Bahkan pihak PUM menggesa agar pihak kerajaan segera mewujudkan Darul Hadis bagi mengawalselia dan menjaga kesucian teks-teks hadith daripada dicemari dengan kepalsuan rekaan manusia. ${ }^{13}$

Selain daripada masalah wujudnya hadith daif dan maudhu', ia menjadi sesuatu yang perlu diberi perhatian apabila penulisan buku-buku motivasi yang menggunakan dalil-dalil hadith tidak dinyatakan sumber dan hukum hadith tersebut. Maka hal ini akan menyumbang kepada penyebaran hadith daif dan maudhu'. Sebagai contoh, hadith-hadith yang terdapat di dalam buku motivasi; Kemabiran Mendidik Anak - Menangani Anak Bermasalah. ${ }^{14}$ Buku tersebut mengemukakan hampir 9 hadith berunsur motivasi, namun 5 hadith daripadanya tidak dinyatakan status hadith walaupun ia menyatakan periwayatan dan selebihnya adalah hadith yang diriwayatkan oleh al-Bukhariyy dan Muslim.

Antara contoh lain, hadith-hadith yang terdapat di dalam buku Petua Mendidik Anak Menjadi Insan Positif. ${ }^{15}$ Terdapat hampir 21 hadith berunsur motivasi, yang mana 2 sahaja hadith yang disebutkan statusnya dan 1 hadith yang dinyatakan periwayatan oleh al-Bukhariyy dalam kitab Adab al-Mufrad . Manakala selebihnya hampir 18 hadith lagi tidak dinyatakan statusnya yang mana 5 daripadanya tidak dinyatakan sumber pengambilannya.

Selain itu, juga boleh berlaku kemungkinan bahawa sesuatu hadith yang diriwayatkan oleh al-Bukhariyy dan Muslim, namun disebabkan kekurangan ilmu berkaitan hadith dan takhrij maka berlaku percampuran antara periwayatan al-Bukhariyy dan periwayatan selain al-Bukhariyy. Bahkan yang lebih menduka-citakan ialah, hadith tersebut tiada langsung diriwayatkan oleh al-Bukhariyy namun menyandarkan kepada periwayatannya agar hadith tersebut diterima. Maka ia sesuatu yang perlu dibendung dan diperbaiki.

Menurut Datuk Dr. Mashitah Ibrahim, walaupun penyebaran hadith palsu melalui pelbagai medium terkawal, namun ia merupakan perbuatan yang merbahaya, mengelirukan, dan mengancam kesucian agama. Bahkan mereka termasuk dalam kalangan orang yang berdusta ke atas Nabi Muhammad s.a.w. Beliau menyatakan demikian ketika diminta mengulas berkaitan dengan

\footnotetext{
${ }^{13}$ Anon, Harakabdaily, 2015. 16 Ogos.Rujuk juga : http://www.harakahdaily.net/index.php/ berita-utama/36942-hadis-palsu-darul-hadis-perlu-disegerakan [16 Ogos 2015]

${ }^{14}$ Dato' Dr. Hj. Mohd. Fadzilah Kamsah et al, 2006.

${ }^{15}$ Dato' Dr. Hj. Mohd. Fadzilah Kamsah et al, 2007b.
} 
penyebaran hadith palsu yang semakin menular di kalangan pengguna internet. $^{16}$

Kelemahan dalam penguasaan sumber ilmu khususnya dalam ilmu hadith boleh memberi kesan sehingga menyebabkan berlakunya penyebaran hadith palsu, masyarakat tidak mengambil cakna berkaitan dengan status hadith, dan munculnya amalan-amalan yang bukan didasari dari Nabi Muhammad s.aw. Agama Islam itu sendiri menitikberatkan penggunaan dalildalil yang sahih supaya penyampaian itu bermatlamat dan berkesan kepada pendengar.

Oleh itu, pengkaji memandang bahawa segala permasalahan ini perlu diambil perhatian. Dan perlunya kajian ini dilakukan bagi memberi peringatan kepada masyarakat agar berhati-hati dan menghindari dari menyebarkan hadith daif dan maudhu'.

\section{Metode Penelitian}

Kajian yang dijalankan ini ialah kajian dokumentasi yang menggunakan pendekatan kualitatif. Pengkaji menggunakan pendekatan kualitatif dalam kajian ini untuk meneroka dan menganalisis ketepatan kandungan hadithhadith di dalam buku motivasi berdasarkan beberapa sebab. Pertama, bentuk ini merupakan bentuk yang sesuai dalam memahami kajian ini secara terperinci. Hal ini kerana bentuk ini mempunyai proses yang tertumpu iaitu permasalahan kajian dan data-data dikumpulkan, kemudian dianalisis. Seterusnya pengkaji menafsirkan data-data tersebut, akhirnya ia menghasilkan keputusan yang diingini. ${ }^{17}$

Kedua, pendekatan kuantitatif mempunyai batasan iaitu, ia terikat dengan statistik atau numeric yang ditemui. ${ }^{18}$ Manakala pendekatan kualitatif lebih meluas. Ketiga, pemilihan bentuk kualitatif juga berdasarkan kepada minat pengkaji untuk meneroka, membuat penemuan dan bukannya untuk menguji hipotesis. Ini selaras dengan tujuan kajian ini iaitu untuk meneroka dan penentukan hadith-hadith yang digunakan di dalam buku-buku motivasi sama ada ia diterima atau ditolak.

Apabila kajian dokumentasi ini dikaitkan dengan pengkajian pengajian Islam, maka kajian dokumentasi tertumpu ke atas manuskrip agama seperti alQuran, hadith dan kitab-kitab agama. Kajian boleh dilakukan sama ada dengan

\footnotetext{
${ }^{16}$ Berita Harian, 2012, hlm. 8.

${ }^{17}$ John W. Creswell, 2013, hlm. 4.

${ }^{18}$ John W. Creswell, 2013, hlm. 4.
} 
menggunakan metode analisis kandungan, perbandingan, kajian persejarahan terhadap isi dan tafsiran al-Quran dan pelbagai kitab tafsir termasuk pengarangnya. Demikian juga kajian terhadap matan dan sanad hadith, kajian takhrij hadith dan sebagainya. ${ }^{19}$ Justeru, kajian ini akan menggunakan metode analisis kandungan, membuat perbandingan di antara sumber primer dan sekunder, dan juga mengaplikasikan kaedah takhrij hadith.

Bagi kajian ini, pengkaji mengambil hadith yang dinukilkan oleh penulis buku dengan membahagikan kepada tiga bahagian, sebagaimana berikut :

1. Hadith yang dinyatakan periwayatan oleh al-Bukhariyy dan Muslim.

2. Hadith yang dinyatakan periwayatan selain periwayatan al-Bukhariyy dan Muslim.

3. Hadith yang tidak dinyatakan periwayatan dari mana-mana periwayatan. Dalam kajian ini, sampel utama yang dipilih terdiri daripada 10 buah buku genre motivasi dari 99 buah buku popular pilihan pembaca. Kesemua buku tersebut diambil dalam tempoh 5 tahun bermula pada tahun 2007 hingga 2011. Kesemua buku tersebut telah mencatatkan jualan tahunan paling laris dengan anggaran 10,000 naskah ke atas. Seterusnya melayakkan kesemua buku tersebut tersenarai dalam 10 finalis karya bukan cereka, dan dipertandingkan di dalam satu acara anugerah anjuran syarikat Popular Book Co (M) Sdn Bhd dengan kerjasama Berita Harian. Acara tersebut diberi nama 'Anugerah Pilihan Pembaca Popular-Berita Harian' bertujuan mengiktiraf, menghargai dan memberi semangat kepada penulis untuk terus berkarya dalam bahasa Melayu. ${ }^{20}$

Berikut adalah senarai buku-buku yang dipertandingkan dan pemenang 'Anugerah Pilihan Pembaca Popular-Berita Harian' dalam tempoh 5 tahun (2007-2011) :

\begin{tabular}{|c|l|c|}
\hline No & \multicolumn{1}{|c|}{ Tajuk Buku } & Bilangan Hadith \\
\hline 1 & Ada Bagus Bagusss (2007) & 2 \\
\hline 2 & Jangan Main-Main (2007) & 6 \\
\hline 3 & Kuasa Hijrah Kuasa Untuk Berubah (2007) & 3 \\
\hline 4 & Fikir-Fikirlah (2008) & 10 \\
\hline 5 & Membina Cinta Sayang (2008) & 8 \\
\hline 6 & Mak, Abah.. Redailah Anakmu (2009) & 28 \\
\hline 7 & Nak Jadi Jadi (2009) & 10 \\
\hline
\end{tabular}

${ }^{19}$ Ahmad Sunawari Long, 2009, hlm. 13.

20 Anon, 2008, Anugerah Pilihan Pembaca Berita Harian-Popular 2008. http://zamrimohamad.com/blog/anugerah-pilihan-pembaca-berita-harian-popular-2008. [27 Oktober 2012] 


\begin{tabular}{|c|l|c|}
\hline 8 & Rabsia Minda Hebat (2009) & 34 \\
\hline 9 & 10 Terminal Syurga Rumah Tangga (2010) & 44 \\
\hline 10 & Oi! Bangunlab Oi! (2011) & 4 \\
\hline & Jumlah & $\mathbf{1 4 9}$ \\
\hline
\end{tabular}

Jumlah Keseluruhan Bilangan Hadith

Kesemua 10 buah buku yang dipilih berdasarkan kepada genre motivasi sahaja. Pengkaji akan menggumpulkan hadith-hadith yang terdapat di dalam buku-buku tersebut. Keseluruhan hadith dalam semua buku-buku motivasi ini berjumlah 149 buah hadith. Data-data dikumpulkan berdasarkan kepada nukilan di dalam buku-buku tersebut yang membawa maksud teks tersebut adalah hadith, seperti 'Nabi/Rasulullah bersabda', 'Nabi menegaskan', 'Nabi menyuruh', 'Kata Nabi', 'Nabi menasihatkan', 'ada hadith meriwayatkan'.

Dalam melakukan proses menganalisis data dan mengaplikasikan kaedah takhrij dalam kajian ini, pengkaji merancang dan mengurus data melalui tiga langkah iaitu; mengurus data, memahami data dan menganalisis data.

Langkah 1 : Mengurus data

Perancangan dan pengurusan data dijalankan melalui beberapa fasa. Berikut dijelaskan secara terperinci fasa-fasa dalam proses pengurusan data. Fasa pertama adalah proses penyaringan data di mana langkah dimulai dengan melihat dan membuat penyalinan dari hadith-hadith yang terdapat di dalam buku motivasi. Proses penyalinan tekstual ini memerlukan kepada pemerhatian yang penuh dan berhati-hati. Ianya bertujuan agar sumber yang diambil tepat dan tidak bias.

Sebaik sahaja proses penyalinan selesai, setiap tekstual yang lengkap dibentukkan indeks. Proses mengindeks tekstual dilakukan dengan melabelkan satu kod tersendiri kepada setiap hadith yang dikaji. Penetapan kod-kod bagi setiap transkrip adalah penting bagi memudahkan proses mendapatkan semula data asal dan memudahkan pengkaji membuat rujukan semula.

Penetapan kod indeks tekstual bagi kajian ini adalah seperti Rajah 1 berikut :

\begin{tabular}{cc}
\hline No & Kod \\
\hline & Analisis Hadith (Nombor Hadith) [Tajuk Buku] [Tahun] hlm. [Nombor \\
& Halaman] \\
& Indeks Kod Pengumpulan Transkrip Hadith
\end{tabular}



pengkaji:

Berikut adalah maksud bagi kod indeks yang dimakudkan oleh

Analisis Hadith (Nombor Hadith) [Tajuk Buku] [Tahun] hlm. [Nombor Halaman] yang membawa maksud Analisis Hadith adalah tajuk, (nombor hadith) merujuk kepada nombor hadith yang ditemui, Tajuk merujuk kepada tajuk buku motivasi yang dirujuk, tahun merujuk kepada tahun buku tersebut diterbitkan, manakala hlm merujuk kepada halaman di mana hadith tersebut diambil, dan yang terakhir [Nombor Halaman]. Sebagai contoh : Analisis Hadith (1) Ada Bagus Bagusss 2007 hlm. 25. Hal yang sama ditetapkan pada analisis seterusnya.

Langkah 2 : Proses memahami data

Pada tahap ini, pengkaji akan cuba memahami data yang telah dikumpulkan dan dikodkan. Setiap data yang berupa teks hadith tersebut akan diteliti secara serius. Hal ini kerana setiap dapatan hadith yang ditemui, tidak semuanya dibawakan sekali bersama teks asal Bahasa Arab. Kebarangkalian hadith yang ditemui hanya dinukilkan secara makna sahaja mungkin berlaku. Maka terdapat dua pendekatan yang dilakukan pengkaji dalam memadankan makna hadith tersebut iaitu, membuat kata kunci dan berdasarkan sangkaan.

Membuat kata kunci merupakan pendekatan yang digunakan oleh pengkaji berdasarkan kepada kaedah asas dalam pencarian takhrij sesuatu hadith itu iaitu ; mentakhrij hadith dengan mengenal pasti kalimah dalam matan hadith. ${ }^{21}$ Kaedah ini merupakan kaedah yang digunakan dengan memilih kalimah yang pelik (gharib) atau lebih menonjol dalam sesuatu hadith. ${ }^{22}$

Setelah kata kunci dibuat, maka pengkaji akan memadankan hadith yang sesuai dengan hadith yang dinyatakan dalam buku motivasi. Sekiranya hadith yang terdapat di dalam buku motivasi sepadan dengan teks hadith Bahasa Arab, pengkaji boleh meneruskan langkah untuk menganalisa hadith tersebut. Sekiranya tidak sepadan, pengkaji akan memulakan semula langkah pencarian kata kunci yang baru.

Pengkaji akan menggunakan pendekatan kedua iaitu bersandarkan sangkaan sekiranya hadith-hadith yang dinyatakan di dalam buku motivasi mengikut kefahaman penulis buku motivasi. Namun pendekatan ini tidak dominan penggunaannya kerana wujud kemungkinan kefahaman penulis terhadap hadith yang dinyatakan merupakan ulasan \& kesimpulan beliau terhadap sesuatu hadith.

\footnotetext{
${ }^{21}$ Muhammad Abu al-Laith al-Khair Ubadiyy, 1420H/1999M, hlm. 41.

22 Faisal Ahmad Shah, 2010, hlm. 79.
} 


\section{Langkah 3 : Menganalisis data}

Pendekatan kajian takhrij merupakan pendekatan paling utama dalam kajian ini. Menurut Mahmud Thahhan, dari sudut ilmu hadith, takhrij merupakan penunjuk kepada sumber-sumber asli hadith dan yang mengarah kepadanya dengan mengemukakan sanad dan kemudian menjelaskan martabatnya jika diperlukan. ${ }^{23}$ Sewaktu pengkaji menganalisis data takhrij terhadap hadith, pengkaji menyandarkan kepada mana-mana sahaja kitab hadith yang mempunyai lafaz yang sehampir mungkin dengan teks hadith yang dibawa dalam buku motivasi. Namun, bagi hadith yang dinyatakan sumber periwayatannya pula, maka pengkaji menjadikan ia sebagai panduan dalam pencarian takhrij tersebut.

Penjelasan data analisis dikemukakan dengan menggunakan beberapa kaedah. Tujuh kaedah ditetapkan oleh pengkaji ketika melakukan penganalisisan data iaitu; pertama, mengemukakan matan hadith dari bukubuku motivasi samaada dengan lafaz hadith atau makna hadith atau keduaduanya sekali. Kedua, melakukan takhrij hadith. Kitab yang digunakan untuk mentakhrij ialah Kutub al-Tis'ah iaitu: Sabih al-Bukhariyy Sabih Muslim, Sunan alTirmidriyy, Sunan Abu Dawud, Sunan al-Nasa'iyy, Sunan Ibn Majah, Sunan alDarimiyy, al-Muwatta', Musnad Abmad bin Hanbal dan juga kitab hadith lain. Namun begitu, sekiranya masih tidak ditemui maksud hadith yang dikehendaki dalam kesemua kitab tersebut, pengkaji meluaskan kepada kitab-kitab al-Targhib wa al-Tarbib dan kitab-kitab sumber primer yang lain.

Sebagai contoh, pengkaji menggunakan dua pendekatan dalam pencarian takhrij hadith iaitu dengan melihat kepada kitab al-Mu'jam al-Mufahras li al-Alfaz al-Hadith al-Nabawiyy karangan A.J. Wensinck dan juga melihat kepada software Maktabah al-Shamilah.

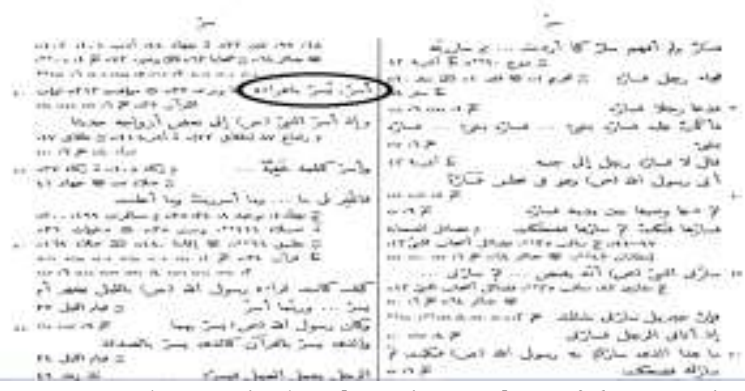

Rajah 1.3 Rujukan Kitab al-Mu'jam al-Mufahras Halaman 446

${ }^{23}$ Mahmud Thahhan, 1991M, hlm. 8. 
Dalam kitab tersebut mengumpulkan hadith-hadith yang ingin dicari dengan dikumpulkan secara ringkasan sebagai contoh (2) membawa maksud riwayat Abu Dawud, (•) membawa maksud riwayat al-Tirmidhiyy, dan $(\sim)$ membawa maksud riwayat Ahmad bin Hanbal.

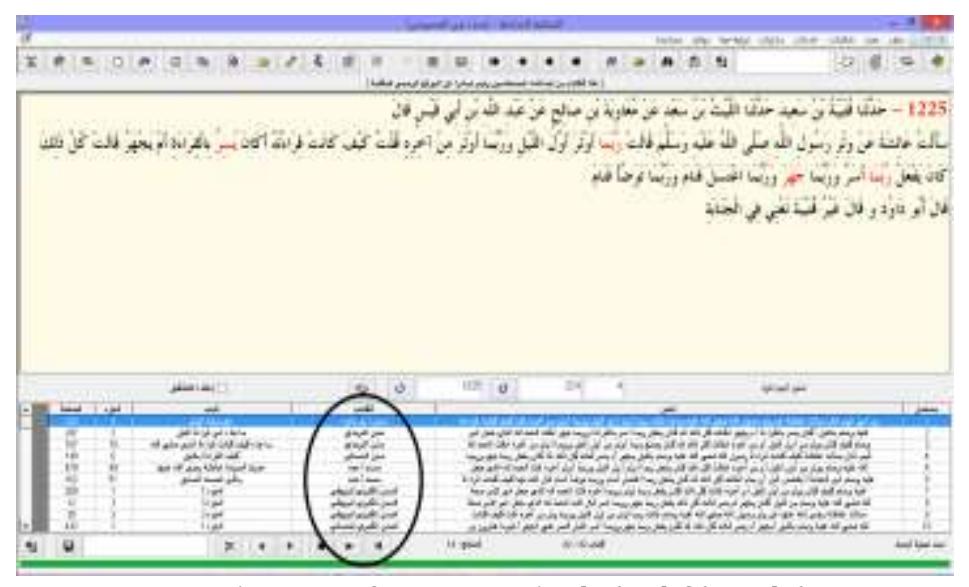

Rajah 1.4 software Maktabah al-Shamilah

Setelah melakukan penelitian terhadap dua pendekatan tersebut, pengkaji mendapati bahawa hadith ini diriwayatkan dengan sanad yang lengkap oleh Abu Dawud, al-Tirmidhiyy, al-Nasa'iyy, Ibn Majah dan Ahmad bin Hanbal. Maka pengkaji melakukan pencarian terhadap kitab-kitab yang telah ditemui.

Ketiga, melakukan analisa terhadap sanad hadith dan mendatangkan shajarah al-Asanid bagi mengukuhkan lagi analisis pada data-data yang ditemui. Keempat, melakukan analisa pada matan hadith. Pengkaji melakukan perbandingan antara matan hadith yang dikemukakan oleh penulis buku-buku motivasi dengan matan yang diriwayatkan di dalam kitab asal hadith. Perbandingan ini bukan bertujuan untuk mencari kesalahan sebaliknya untuk menjelaskan perbezaan matan hadith yang diriwayatkan dan mengetahui metode penulis buku ketika menukilkan hadith.

Kelima, memberikan hukum hadith dan ta'liq (komentar pengkaji). Pengkaji menyatakan hukum bagi semua hadith yang ditakhrijkan dengan menyandarkannya kepada mana-mana muhaddith (ahli hadith) yang berkaitan. Sekiranya dikenalpasti sesebuah hadith itu adalah riwayat al-Bukhariyy dan 
Muslim, maka akan dinyatakan takhrij hadith tersebut sahaja tanpa meletakkan status hadith.

Seterusnya, bagi sesuatu hadith diriwayatkan dari kitab selain alBukhariyy dan Muslim, maka ia dihukum mengikut hukum yang telah dinyatakan oleh penulis kitab hadith tersebut seperti hadith-hadith yang telah ditentukan hukumnya oleh al-Tirmidziyy dalam Sunan al-Tirmidzri. Namun begitu, pengkaji juga akan mengemukanan hujjah jika hukum yang dinyatakan terdapat hukum lain dari para ulama hadith sebagai perbandingan. Apabila penulis kitab tidak menyatakan hukum bagi sesuatu hadith yang dikaji, maka hadith tersebut dinilai berdasarkan hukum yang telah ditentukan oleh para ulama yang mentahqiq hadith tersebut seperti Ahmad Muhammad Shakir, alAlbaniyy, al-Arna'uth, atau selainnya.

Bagi hadith yang tidak ditemui hukumnya daripada mana-mana ulama hadith, maka pengkaji menganalisa keadaan sanadnya berpandukan komentar ulama al-Jarh wa al-Ta'dil (mencacat dan membersihkan kedudukan seseorang periwayat hadis). Berdasarkan komentar ulama al-Jarh wa al-Ta'dil seperti Abu Hatim, Abu Hajar dan selainnya dan penjelasan hukum hadith tersebut, pengkaji seterusnya menghukumkan sesuatu hadith. Sebagaimana contoh ketika mana Abu Hatim mengkritik seorang perawi bernama Ali bin Asim, beliau menyatakan Ali bin Asim sebagai Layyin al-Hadith yakni lemah dalam hadith. ${ }^{24}$ Pernyataan ini disokong oleh Ibn Hajar ketika beliau menukilkan katakata beberapa orang yang mengkritik Ali bin Asim antaranya; Ya'qub bin Shaybah dan Ibn al-Madiniyy berkata: Kathrat al-Khata' wa al-Ghalat yakni banyaknya kesilapan dan percampuran. Salih bin Muhammad pula berkata : Beliau bukan dikalangan pendusta tetapi dituduh berdusta, buruk hafalan, banyaknya keraguan, dan hadith-hadithnya bercampur. ${ }^{25}$

Penetapan status hukum hadis ini penting untuk memastikan sama ada sesuatu hadis itu boleh diterima atau tidak. Pengkaji hanya menghukumkan sesuatu hadith berdasarkan riwayat yang telah dikemukakan pada sesuatu perbincangan tertentu dan tidak menolak kemungkinan bahawa hadis yang telah dihukumkan itu boleh bertukar statusnya kepada sahih, hasan dan lainnya melalui jalur periwayatan yang lain.

Keenam, mengemukakan penilaian dan kesimpulan terhadap hukum dan ta'liq yang dilakukan oleh ulama hadith. Dan yang terakhir yakni ketujuh, mengemukakan Shawahid \& Mutaba'at dan hadith lain yang membawa makna

\footnotetext{
24 Abu Hatim, 1373H/1953M, Jil. 6, hlm. 198-199.

25 Ibn Hajar, t.th.a, Jil.3, hlm. 173-174.
} 
yang sama sebagai alternatif dan cadangan kepada penggunaan hadith-hadith yang dinilai da'if dan maudhu' di dalam kajian ini jika perlu.

\section{Dapatan Kajian dan Perbincangan}

Berdasarkan kepada kajian keatas 123 buah hadith termasuk hadith yang diulang sebut oleh penulis buku-buku motivasi daripada jumlah keseluruhan 149 buah hadith yang ditemui, pengkaji mengemukakan hasil dapatan kajian dan perbincangan yang dapat dikeluarkan daripada kajian ini. Perbincangan kajian ini adalah tertumpu pada aspek bilangan hadith dari segi kategori hukumnya, jumlah dan bilangan peratusan hadith mengikut statusnya.

Penelitian keatas 123 buah hadith mendapati bahawa terdapat 75 buah hadith dinilai sebagai maqbul (sahih dan hasan), 42 buah hadith mempunyai masalah pada sanad, dan baki 6 buah hadith tidak dapat ditentukan statusnya. 75 buah hadith maqbul tersebut dipecahkan kepada 12 buah hadith muttafaqun alayhi, 27 buah hadith sahih, 31 buah hadith hasan, dan 5 buah hadith sahih li ghayrihi. Manakala 42 buah hadith yang mempunyai masalah pada sanad dipecahkan kepada 32 buah hadith da'if, 6 buah hadith da'if jiddan dan 4 buah hadith mawdu'. Seterusnya baki 6 buah hadith yang tidak dapat ditentukan statusnya kerana pengkaji tidak menemui periwayatan hadith tersebut di dalam mana-mana kitab hadith. Jadual berikut menunjukkan ringkasan tentang kategori status hadith dan jumlah bilangannya serta peratusan yang diperoleh daripada kajian keatas 123 buah hadith:

Jadual 1.10 Pembahagian Status Hadith

\begin{tabular}{lcc}
\hline Hukum & Bilangan Hadith & Peratus (\%) \\
\hline Muttafaqun Alayhi & 12 & $9.8 \%$ \\
Sahih & 27 & $22 \%$ \\
Hasan & 31 & $25.2 \%$ \\
Sahih li Ghayrihi & 5 & $4 \%$ \\
Da'if & 32 & $26 \%$ \\
Da'if Jiddan & 6 & $4.9 \%$ \\
Mawdu' & 4 & $3.2 \%$ \\
Tidak dikenalpasti & 6 & $4.9 \%$ \\
\hline Jumlah & 123 & $100 \%$ \\
\hline
\end{tabular}


Berikut pula adalah rajah bagi ringkasan untuk hadith yang maqbul dan mardud :

Rajah 1.11 Ringkasan Hadith Maqbul dan Mardud

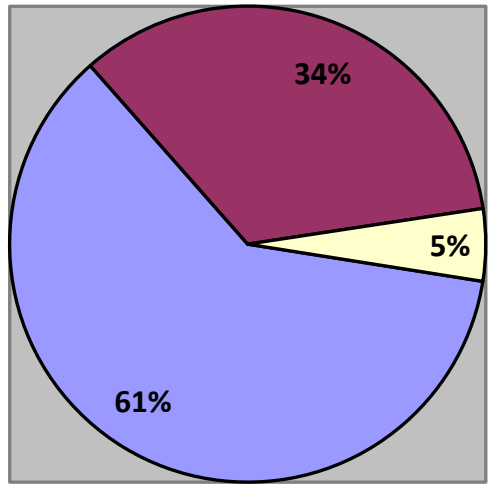

\begin{tabular}{|l|}
\hline$\square$ Hadith maqbul \\
$\square$ Hadith yang \\
mempunyai masalah \\
sanad \\
$\square$ Hadith yang tidak \\
dapat dikenalpasti \\
statusnya
\end{tabular}

Melalui jadual 1.10 dan rajah 1.11, pengkaji dapat menyimpulkan bahawa status hadith maqbul mendominasi hadith yang lain dalam kajian ini.

\section{Simpulan}

Keseluruhan hadith dalam buku-buku motivasi berjumlah 149 buah hadith. Namun begitu, pengkaji hanya melakukan kajian ke atas 123 buah hadith sahaja kerana baki 26 buah hadith merupakan hadith yang berulang. Berdasarkan analisis status hadith terhadap 123 buah hadith tersebut, pengkaji mendapati 75 buah hadith dinilai sebagai maqbul (sahih dan hasan), 42 buah hadith mempunyai masalah pada sanad, dan baki 6 buah hadith tidak dapat ditentukan statusnya. Kajian ini merupakan satu sumbangan kepada penulisan pengajian Islam bagi membolehkan para pembaca mengetahui status hadith yang dikemukakan dalam buku-buku motivasi samaada ia diterima atau ditolak. Pembaca dapat menilai hujah-hujah yang dikemukan secara ilmiah. Kajian ini juga memberi kesedaran kepada para pembaca agar lebih peka terhadap penggunaan hadith, kerana tidak semua yang disandarkan kepada Rasulullah boleh diterima dan ia perlu dikenalpasti statusnya.

Selain itu, kajian ini juga dapat menyediakan satu garis panduan bagi para penulis buku-buku genre motivasi untuk mengemukakan hadith ke dalam karya-karya mereka. Ia akan memberi manfaat kepada penulis yang tiada latar 
belakang pengajian Islam dan pengajian hadith dalam menghasilkan karya yang lebih baik dan bermutu. Harapan pengkaji supaya ia dapat membendung gejala menyampaikan hadith-hadith palsu dan hadith-hadith yang tiada sandaran padanya.

\section{Daftar Pustaka}

Al-Quran al-Karim

Abu Hatim, 'Abd al-Rahmnn bin Abu Hatim. 1373H/1953M. al-Jarh wa alTa'dil. Jil. 1-9. Pthq. Abd al-Rahman bin Yahya. Bayrut: Dar al-Kutub al-'Ilmiyyah.

Ahmad Asmadi Sakat, M. Z. Mohd Zin, Ahmad Faisal Mahdi, Mohd Roslan Mohd Nor, N. Azlina Ahmad, Mohd Arif Nazri, Muhd Najib Abdul Kadir, Nurfarhah Zainan Nazri \& Azri Bhari. 2012M. Comparison of Western Motivation Theories with Islamic Method. Journal of Applied Sciences Research. 8(7): 3249-3252.

Ahmad Sunawari Long. 2009. Pengenalan Metodologi Pengkajian Pengajian Islam. Bangi:Penerbit FPI Universiti Kebangsaan Malaysia.

Amal Hayati Ishak \& Suraiya Ishak. 2009. Konsep Ganjaran dan Motivasi Menurut Perspektif Islam. Jurnal Fikrah: Centre for Islamic Thought and Understanding. Jilid 4 (Disember 2009), hlm. 187-203. Shah Alam: Universiti Teknologi MARA(UiTM)

Anon. 2001. Tafsir Pimpinan al-Rabman kepada Pengertian al-Quran. Ed. Ke-12. Kuala Lumpur: Jabatan Kemajuan Islam Malaysia (JAKIM).

Anon. 2008. Anugerah Pilihan Pembaca Berita Harian-Popular 2008.http://zamrimohamad.com/blog/anugerah-pilihan-pembacaberita-harian-popular- 2008. [27 Oktober 2012]

Anon. 2008. Rezeki Anugerah Pilihan Pembaca Berita Harian-Popular 2008.http://ptsmarketing.blogspot.sg/2008/05/rezeki-anugerahpilihan-pembaca-berita.html [27 Oktober 2012]

Anon. 2009. Anugerah Buku Pilihan Pembaca Popular Berita Harian 2009. http://telagabiru-tbsb.blogspot.sg/2009/08/anugerah-bukupilihan-pembaca-popular.html [27 Oktober 2012]

Anon. 2009. Anugerah Pilihan Pembaca 2009. http://thebookaholic. blogspot.sg/2009/05/anugerah-pilihan-pembaca-2009.html $[27$ Okober 2012] 
Anon. 2009. Berita Harian. - Nasional. 27 Ogos. http://www.bharian.com.my/ Thursday/Nasional/20090827001213/Article/index_html [27 Oktobr 2012]

Anon. 2012. Penyebaran Hadis Palsu Bahaya, Mengelirukan. Berita Harian Nasional, 21 Februari. Kuala Lumpur.

Anon. 2012. Buku 100 Pesanan Terakhir Rsulullah Tempat Kedua Anugerah Pilihan Pembaca Popular-Berita Harian 2012. https://muhdnasruddin. wordpress.com/2012/09/22/buku-100-pesanan-terakhir-rasulullah tempat-kedua-anugerah-pilihan-pembaca-popular-berita-harian-2012a/ [27 Oktober 2012].

Anon. 2015. Harakahdaily. Hadis Palsu: Darul Hadis perlu disegerakan. http://www.harakahdaily.net/index.php/berita-utama/36942-hadis palsu-darul-hadis-perlu-disegerakan. [16 Ogos 2015]

Al-Bukhariyy, Muhammad bin Isma'il. 1417H/1997M. Shahih al-Bukbariyy. Pnyt. Muhammad bin 'Ali al-Qub, Hisham al-Bukhariyy. Jil. 1-5. Beirut: al-Maktabah al- 'Amariyyah.

Al-Bukhariyy, Muhammad bin Isma'il. 1423H/2002M. Shahih al-Bukhariyy. Dimashq: Dar Ibn Kathir.

Al-Dhahabiyy, Muhammad bin Ahmad. 1996. al-Muntaqa min Minhaj al-I'tidal fi Naqd Kalam Abl al-Rafd wa al-tizal wa huwa Mukhtasar Minhaj alSunnah. Al-Riyad: Dar 'Ilm al-Kutub.

Faisal Ahmad Shah. 2010. Takhrij Hadith : Teknik Pencarian Hadith Yang Tepat dan Berkesan. Kuala Lumpur: Jabatan al-Quran dan al-Hadith, Akademi Pengajian Islam, Universiti Malaya.

Harakah Daily. 2015. 16 Ogos.

Harian Metro. 2015. 14 Ogos.

Helmi. 2010. Anugerah Pilihan Pembaca Popular - Berita Harian 2010 Tingkatkan Semangat Penulis Malaysia. http://pts.com.my/berita/ news-title/ [27 Oktober 2012].

Ibn Hajar, Ahmad bin Ali bin Hajar. t.th.a. Tahdhibu al-Tabdbib. Jil. 1-4. Pthq. Ibrahim al-Zaybaq \& 'Adil Murshid. Bayrut: Mu'assasat al-Risalah.

Ibn al-Jauziyy, 'Abd al-Rahman bin 'Ali. 1386H/1966M. al-Maudhu'att. Pthq. 'Abd al-Rahman Muhammad 'Uthman. al-Madinah al-Munawwarah: alMaktabah al-Salafiyyah.

Jawiah Dakir, Prof Datin Paduka Dr. 2014. Keberadaan al-Mawdu dalam Masyarakat Melayu. Bangi: Penerbit Universiti Kebangsaan Malaysia. 
John W. Creswell. 2013. Research Design : Qualitative, Quantitative, and Mixed Methods Approaches. Ed.4. California: SAGE Publications, Inc.

Latifah Arifin. 2012. Anugerah Pilihan Pembaca Popular-Berita Harian 2012. http://bukuriamalaysia.com/bibliografibuku/anugerah-pilihanpembaca-popular-berita-harian-kembali-2012-mac-27/[27 Oktober 2012]

Mahaizura Abd Malik. 2015. Hadith Palsu : Kongsi Dosa Berantai. Harian Metro, 14 Ogos: 6.

Mahaizura Abd Malik. 2015. Hadith Palsu : Kongsi Dosa Berantai. Harian Metro, 14 Ogos. http://bit.ly/metro14ogos [14 Ogos 2015].

Mahmud al-Thahhan. 1417H/1996M. Taysir Mushthalah al-Hadits. Al-Riyadh: Maktabah al-Ma'arif li al-Nashr wa al-Tawzi'.

Mienfitri. 2008M (September 22). Penawar Hati 2 - Rangsang Perubahan(Astro Oasis). Youtube: http://www.youtube.com/watch?v $=\mathrm{m} 614 \mathrm{vXM6fAg}$. [21 Jun 2012]

Mohamad Hasbullah Salim \& Mohd Aizul Yaakob. 2011. Penggunaan Hadith Da'if Di Dalam Aspek al-Targhib wa al-Tarbib: Kajian Terbadap Kitab Lubab al-Hadith Karya Sheikh Abu Bakar Palestin. Dlm. Sunnah Nabi: Realiti dan Cabaran Semasa, hlm 543-556. Seminar Antarabangsa Sunnah Nabawiah: Realiti dan Cabaran Semasa (MUSNAD). [12 \& 13 Julai 2011]. Kuala Lumpur: Universiti Malaya.

Mohd Fadzilah Kamsah, Muhammad Zakaria \& Maheran Makhtar. 2006. Kemahiran Mendidik Anak-Menangani Anak Bermasalah. Kuala Lumpur: Telaga Biru Sdn. Bhd.

Mohd Fadzilah Kamsah, Muhammad Zakaria \& Husna Hassan. 2007b. Petua Mendidik Anak Menjadi Insan Positif. Kuala Lumpur: Telaga Biru Sdn. Bhd.

Mohd Khairul Nizam Zainan Nazri. 2007. Reward and Punishment in Shabih alBukbari: Thematic Study. Disertasi Sarjana Ilmu Wahyu (al-Quran dan alSunnah). Gombak: Universiti Islam Antarabangsa Malaysia.

Mohd Khairul Nizam. 2012. Motivasi Gaya Rasulullah. Batu Caves: PTS Millennia Sdn Bhd.

Muhammad Abu al-Laith al-Khair Abadiyy, Dr. 1420H/1999M. Takbrij alHadith : Nash'atubu wa Manbajizyatubu. Bangi: Darulsyakir.

Najibah. 2010M. Anugerah Pilihan Pembaca Popular - Berita Harian 2010. http://www.goodreads.com/topic/show/358281-anugerah-pilihanpembaca-popular---berita-harian-2010 [27 Oktober 2012] 
Nazmi Yaakub. 2008. Berita Harian - Nasional. 28 Mei.http:// bharian.com.my/Current_News/BH/Wednesday/Nasional/20080528 081321/Article/ [27 Oktobr 2012]

Roziyah Mahamad. 2011a. Anugerah Penulis Dapat Sambutan: Popular Rancang Tambah Kategori. http://pts.com.my/index.php/berita/ anugerah-penulis-dapat-sambutan-popular-rancang-tambah-kategori [27 Oktober 2012]

Roziyah Mahamad. 2011b. Penulis Berentap Dalam Anugerah Pilihan Pembaca Popular-Berita Harian 2011. http://pts.com.my/berita/penulisberentap-dalam-anugerah-pilihan-pembaca-popular-berita-harian2011/ [27 Oktobr 2012]

Shahfizal Musa, 2014. Syarahan Perdana: Hadis Palsu dalam Masyarakat Melayu. http://www.ukm.my/news/News_Category/syarahanperdana/ [15 September 2014]

Sharaf Muhammad al-Qadah, Dr. 1428H/2007M. al-Manhaj al-Hadith Fi Ulum al-Hadith. Kuala Lumpur: al-Bayan Corporation Sdn. Bhd.

Sulaiman Muhammad Hasan. 2003. Tahqiq dan Takbrij Kitab Hidayat al-Habib fi al-Targhib wa al-Tarbib Oleh Syeikh Nur al-Din al-Raniri. Disertasi Sarjana Pengajian Islam. Bangi: Universiti Kebangsaan Malaysia. 